\title{
Effect of alcohol on glucose, insulin, free fatty acid and triacylglycerol responses to a light meal in non-insulin-dependent diabetic subjects
}

\author{
BY CHRISTIAN CHRISTIANSEN ${ }^{1,2}$, CLAUS THOMSEN ${ }^{1}$, OLE RASMUSSEN ${ }^{3}$, \\ CATRINE HAUERSLEV ${ }^{2}$, METTE BALLE ${ }^{2}$ CARSTEN HANSEN ${ }^{4}$ AND KJELD \\ HERMANSEN ${ }^{2 *}$ \\ ${ }^{1}$ Institute of Clinical Experimental Research, Aarhus University, ${ }^{2}$ Medical Department III and \\ ${ }^{3}$ Medical Department $M$ (Departments of Diabetes and Endocrinology), Aarhus University \\ Hospital, Tage Hansensgade 2, DK-8000, Aarhus C, Denmark, ${ }^{4}$ Department of Forensic \\ Toxicology, Aarhus University, Denmark
}

(Received 22 January 1993-Revised 23 April 1993-Accepted 7 May 1993)

\begin{abstract}
Alcohol accounts for 4-6\% of the average energy intake in most Western countries. Alcohol-induced hypoglycaemia is a well-known and feared complication in insulin-dependent diabetic subjects, but little attention has been paid to the impact of alcohol on carbohydrate metabolism in non-insulin-dependent diabetes. The aim of the present study was to investigate in non-insulin-dependent diabetic subjects the acute metabolic effects of a moderate amount of alcohol taken with a light meal, conditions chosen to mimic an everyday situation. The patients received $500 \mathrm{ml}$ non-alcoholic beer with an alcohol content $(\mathrm{ml} / \mathrm{l})$ of 0 (treatment $\mathrm{A}$ ) and 54 (treatment B) together with a light meal, implying identity of the contents of ingredients except for alcohol. We found similar serum glucose, insulin, free fatty acid and triacylglycerol responses irrespective of addition of a modern amount of alcohol. In conclusion, a moderate amount of alcohol can be taken with a meal without eliciting hypoglycaemia in non-insulindependent diabetic subjects.
\end{abstract}

Non-insulin-dependent diabetes mellitus: Blood biochemistry: Alcohol: Man

Alcohol consumption plays a significant role in the social life of different societies and constitutes a normal part of meals in many regions. It accounts for $4-6 \%$ of the total energy intake in most Western countries (Bebb et al. 1971; Windham et al. 1983; Block et al. 1985; Thomson et al. 1988), which makes it relevant to study the metabolic consequences in diabetes mellitus. It is well known that long-term intake of large amounts of alcohol has adverse effects, e.g. weight gain, hypertriacylglycerolaemia and hepatic cirrhosis. The risk of acute hypoglycaemia after alcohol intake is well established in subjects suffering from insulin-dependent diabetes mellitus (IDDM; Freinkel et al. 1965; Walsh \& O'Sullivan, 1974; Nikkilä \& Taskinen, 1975; Connor \& Marks, 1985), while little is known about the influence of alcohol on metabolism in non-insulin-dependent diabetes mellitus (NIDDM; Friedenberg et al. 1971; Walsh \& O'Sullivan, 1974; McMonagle \& Felig, 1975; Gin et al. 1992). Consequently, the recommendations provided about alcohol intake in NIDDM subjects is often rather vague and based on dogma rather than on scientific results. Previously we have demonstrated in NIDDM that alcohol taken without a meal 
stimulates insulin secretion dose-dependently without suppressing blood glucose levels (Christiansen et al. 1993), the results corroborating those of Walsh \& O'Sullivan (1974). Others have found slightly diminished blood glucose concentrations (McMonagle \& Felig, 1975; Gin et al. 1992).

The aim of the present study was to evaluate the acute metabolic effects of alcohol taken with a light meal in NIDDM subjects.

\section{SUBJECTS AND METHODS}

Subjects

The study included ten NIDDM patients (five women, five men) fully informed of the experimental nature of the investigation which had approval from the local Ethics Committee. Their clinical characteristics are given in Table 1. None of the subjects had diabetic complications except for background retinopathy. Three patients were treated with diet alone, while three also took sulphonylurea, one took metformin and three took a combination of the two agents. No one experienced flushing during the experiments. All participants had endogenous insulin production with postprandial serum C-peptide levels above $1100 \mathrm{pmol} / 1$. None of the participants had a history of liver disease or alcohol abuse.

\section{Experimental protocol}

The subjects participated in random order in the two treatments A and B. After an overnight fast the participants consumed $100 \mathrm{~g}$ white bread ( $50 \mathrm{~g}$ carbohydrate), $20 \mathrm{~g}$ lowfat margarine, $40 \mathrm{~g}$ ham and $500 \mathrm{ml}$ non-alcoholic-beer (NAB; Wiibroe Breweries, Elsinore, Denmark) containing $1900 \mathrm{~kJ}$. In treatment B ethanol was added to the NAB to attain an alcohol content of $54 \mathrm{ml} / 1$, i.e. $24 \mathrm{~g}$ alcohol having an energy content of $700 \mathrm{~kJ}$. The patients took their prescribed medicine at 08.00 hours and consumed the meal within $10 \mathrm{~min}$.

Blood samples for glucose, serum insulin, free fatty acid (FFA), triacylglycerol and ethanol analyses were collected from a cubital vein every $15 \mathrm{~min}$ from 07.30 to 08.30 hours and every $30 \mathrm{~min}$ from 08.30 until 12.00 hours. The samples were stored at $-20^{\circ}$ until required for analysis. Urine was collected from 08.00 to 12.00 hours to determine the urinary glucose excretion.

\section{Analytical methods}

Plasma and urinary glucose concentrations were measured by a glucose oxidase (EC 1.1.3.4) method and serum insulin levels by a specific radioimmunoassay (Ørskov et al. 1968). $\mathrm{HbA}_{1 \mathrm{C}}$ was measured by ion-exchange chromatography (Bio-Rad, Richmond, CA, USA); normal range $3 \cdot 5-5 \cdot 5 \%$ ). FFA and triacylglycerols were determined using standard enzymic colorimetric commercial assay kits (Wako Chemicals, Germany and Boehringer Mannheim, Germany). Serum ethanol was determined by gas-liquid chromatography using a head-space technique (Machata, 1975).

\section{Statistical methods}

The blood glucose and serum insulin responses are expressed as the incremental area above the fasting concentration (AUC). The concentrations of serum FFA and triacylglycerols are given as mean values for the entire study period. Serum ethanol is expressed as peak concentration values. The fasting concentrations were the mean values between 07.30 and 
Table 1. Clinical data for the ten non-insulin-dependent diabetic subjects

(Mean values with their standard errors for five male and five female subjects)

\begin{tabular}{|c|c|c|c|c|c|c|c|c|c|c|c|}
\hline \multirow{2}{*}{\multicolumn{2}{|c|}{$\begin{array}{l}\text { Duration of } \\
\text { diabetes } \\
\text { (years) }\end{array}$}} & \multirow{2}{*}{\multicolumn{2}{|c|}{$\begin{array}{c}\text { Age } \\
\text { (years) }\end{array}$}} & \multirow{2}{*}{\multicolumn{2}{|c|}{ BMI $\left(\mathrm{kg} / \mathrm{m}^{2}\right)$}} & \multirow{2}{*}{\multicolumn{2}{|c|}{$\mathrm{HbA}_{1 \mathrm{C}}(\%)$}} & \multicolumn{4}{|c|}{$\begin{array}{l}\text { Fasting blood glucose } \\
\qquad(\mathrm{mmol} / \mathrm{l})\end{array}$} \\
\hline & & & & & & & & \multicolumn{2}{|c|}{ Treatment A } & \multicolumn{2}{|c|}{ Treatment B } \\
\hline Mean & $S E$ & Mean & $\mathrm{SE}$ & Mean & $\mathrm{SE}$ & Mean & $\mathrm{SE}$ & Mean & $\mathrm{SE}$ & Mean & $\mathrm{SE}$ \\
\hline 6 & 2 & 55 & 3 & $29 \cdot 0$ & $1 \cdot 2$ & 7.0 & 0.4 & $9 \cdot 0$ & $1 \cdot 0$ & $9 \cdot 5$ & $1 \cdot 1$ \\
\hline
\end{tabular}

BMI, body mass index (weight/height ${ }^{2}$ ); $\mathrm{HbA}_{1 \mathrm{C}}$, glycosylated haemoglobin $\mathrm{A}_{1 \mathrm{c}}$.

Table 2. Metabolic responses in ten non-insulin-dependent diabetic subjects receiving $500 \mathrm{ml}$ non-alcoholic beer with an alcohol content of 0 (treatment A) or 54 (treatment B) $m l / l^{*}$

(Glucose and insulin values are given as incremental area under curve (AUC), triacylglycerols and free fatty acids (FFA) as average concentrations, ethanol as maximum value and urinary glucose as total amount in a $240 \mathrm{~min}$ time-period following eating. Values are means with their standard errors)

\begin{tabular}{|c|c|c|c|c|c|}
\hline \multirow[t]{2}{*}{ Treatment... } & \multicolumn{2}{|c|}{ A } & \multicolumn{2}{|c|}{ B } & \multirow{2}{*}{$\begin{array}{c}\text { Statistical } \\
\text { significance } \\
\text { of difference } \\
P\end{array}$} \\
\hline & Mean & SE & Mean & SE & \\
\hline Glucose $(\mathrm{mmol} / \mathrm{l})$ & 554 & 69 & 574 & 89 & NS \\
\hline Insulin $(\mathrm{pmol} / \mathrm{l})$ & 6716 & 884 & 8252 & 1193 & NS \\
\hline $\begin{array}{l}\text { Triacylglycerols } \\
(\mathrm{mmol} / \mathrm{l})\end{array}$ & 1.74 & 0.23 & 1.79 & 0.23 & NS \\
\hline FFA $(\mu \mathrm{mol} / 1)$ & 518 & 50 & 423 & 37 & NS \\
\hline $\begin{array}{l}\text { Peak ethanol } \\
(\mathrm{mmol} / \mathrm{l})\end{array}$ & 0.00 & $0-00$ & $9 \cdot 1$ & $0 \cdot 7$ & $<0.01$ \\
\hline $\begin{array}{l}\text { Urinary glucose } \\
(\mathrm{mmol})\end{array}$ & $13 \cdot 5$ & 6.7 & 20.8 & $9 \cdot 7$ & NS \\
\hline
\end{tabular}

NS, not significant.

* For details of subjects and procedures, see Table 1 and pp. 450-451.

08.00 hours. The results are expressed as means with their standard errors. A two sample $t$ test was used for statistical analysis, and $P=0.05$ was considered significant.

\section{RESULTS}

All subjects had both treatments ( $\mathrm{A}$ and $\mathrm{B}$ ) adhered well to the timing, and consumed the meals completely. There were no significant differences in fasting concentrations of serum glucose, insulin, triacylglycerols or FFA. There were no traceable amounts of ethanol in the fasting blood samples.

The effects of treatments $\mathrm{A}$ and $\mathrm{B}$ on metabolic responses are shown in Table 2. As illustrated in Fig. 1, blood glucose responses were superimposable. The alcohol-containing meal was associated with a slight increase in insulin concentrations compared with the 

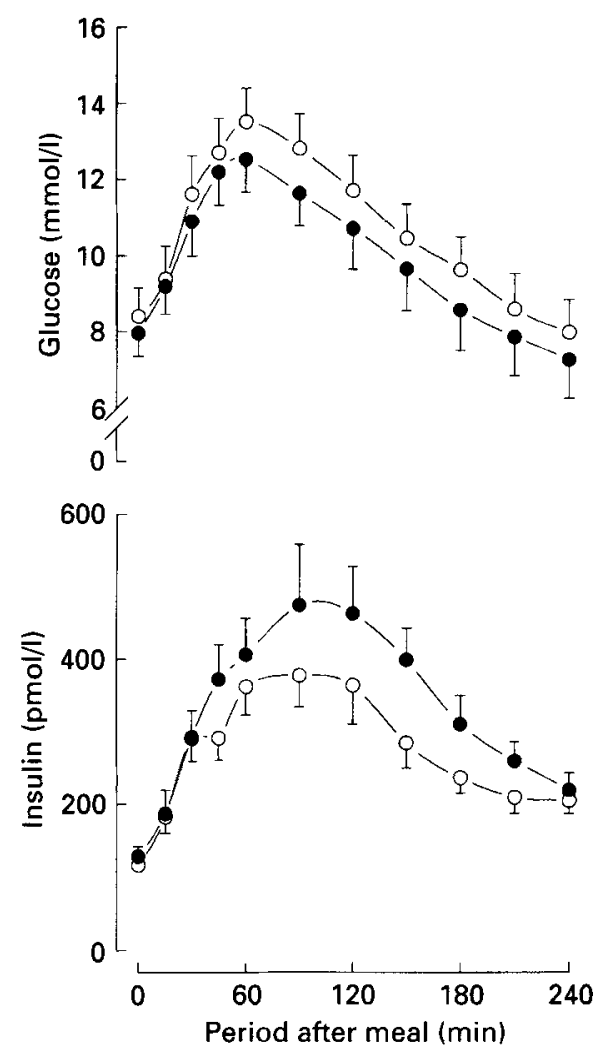

Fig. 1. Effects of $500 \mathrm{ml}$ beer containing $0(\mathrm{O}-\mathrm{O})$ and $54(-\mathrm{ml}$ ethanol $/ 1$ taken with a light meal on blood glucose and serum insulin responses in ten non-insulin-dependent diabetic subjects. Values are means with their standard errors represented by vertical bars. For details of subjects and procedures, see Table 1 and pp. $450-451$.

alcohol-free meal; however, this was not significant. Concentrations of serum triacylglycerols and FFA were similar after the two treatments (Fig. 2). Urinary glucose excretion was similar with the two treatments. Fig. 3 illustrates differences in serum ethanol levels.

\section{DISCUSSION}

Alcohol possesses the ability to induce hypoglycaemia in normal and insulin-dependent diabetic subjects (Freinkel et al. 1965; Walsh \& O'Sullivan, 1974; Nikkilä \& Taskinen, 1975; Connor \& Marks, 1985), mainly because it effectively inhibits gluconeogenesis in the liver (Yki Järvinen et al. 1988). This effect is more pronounced when the liver is depleted of glycogen, for example in chronic alcoholism and fasting (Freinkel et al. 1965).

In short-term studies moderate doses of ethanol have been found either to diminish slightly (McMonagle \& Felig, 1975; Gin et al. 1992) or not affect blood glucose responses in NIDDM subjects (Walsh \& O'Sullivan, 1974; Christiansen et al. 1993).

The design of the present study implied that the patients received identical amounts of dietary carbohydrate in the two treatments, whereas the total energy load was increased by the added ethanol. The amount of food was chosen to mimic an everyday normal light meal. 

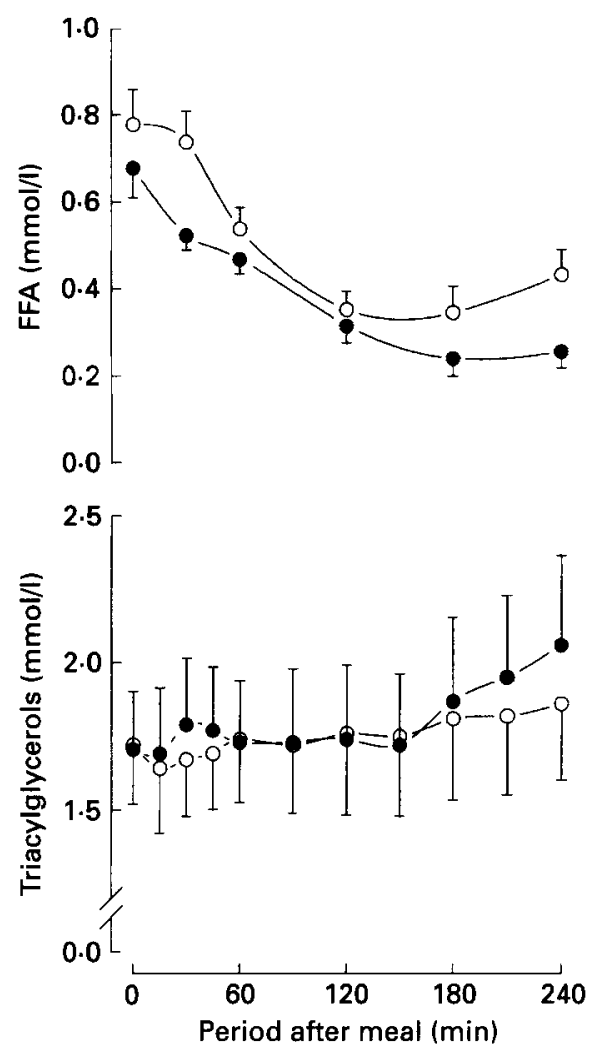

Fig. 2. Changes in serum free fatty acids and triacylglycerols in ten non-insulin-dependent diabetic subjects after intake of $500 \mathrm{ml}$ beer containing $0(\mathrm{O}-\mathrm{O})$ and $54\left(\mathrm{O}_{-}\right) \mathrm{ml}$ ethanol/l ingested with a light meal. Values are means with their standard errors represented by vertical bars. For details of subjects and procedures, see Table 1 and pp. $450-451$.

Our findings indicate that the postprandial blood glucose response is unaffected by moderate amounts of alcohol consumed with a light meal. Some have reported similar results (Walsh \& O'Sullivan, 1974), while others found slightly diminished serum glucose concentrations when comparable amounts of alcohol had been taken with a meal (McMonagle \& Felig, 1975; Gin et al. 1992). Even though hypoglycaemia is a well-known complication in sulphonylurea-treated NIDDM, there is, to our knowledge, no report of hypoglycaemia in NIDDM associated with intake of moderate doses of alcohol either with or without simultaneous food intake.

Recently we demonstrated that $500 \mathrm{ml}$ non-alcoholic beer containing 0,27 and $54 \mathrm{ml}$ alcohol/1 caused a dose-dependent stimulation of insulin secretion in NIDDM subjects (Christiansen et al. 1993). In the present study it appears that a light meal extensively dilutes or eliminates the insulinogenic effect of moderate alcohol intake in NIDDM. Furthermore, no difference in FFA and triacylglycerol concentrations was seen.

The present results indicate that a moderate amount of alcohol does not acutely reduce the glycaemic control in NIDDM and it seems safe for NIDDM patients to consume moderate amounts of alcohol with a meal without risking hypoglycaemia. In the long term, however, one must bear in mind the energy content of beer and alcohol, i.e. consider the potential of alcohol to increase body weight, especially in overweight and obese NIDDM subjects. 


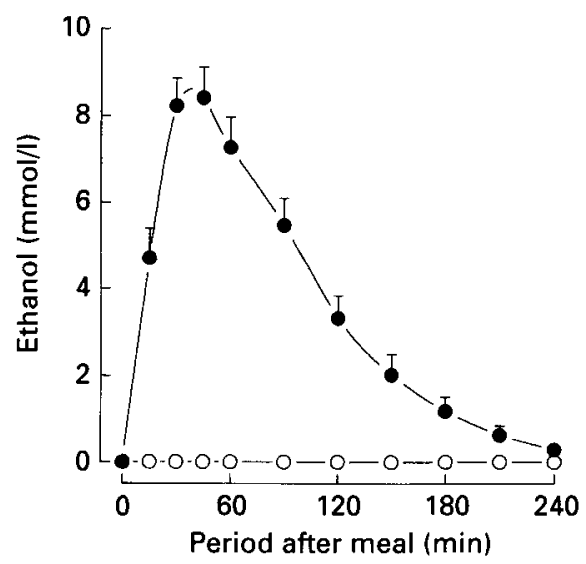

Fig. 3. Serum ethanol levels in response to intake of a light meal and $500 \mathrm{ml}$ beer containing $0(\mathrm{O}-\mathrm{O})$ and 54 (-) $\mathrm{ml}$ ethanol/1 in ten non-insulin-dependent diabetic subjects. Values are means with their standard errors represented by vertical bars. For details of subjects and procedures, see Table 1 and pp. $4, \mathrm{~J}-451$.

\section{REFERENCES}

Bebb, H. T., Houser, H. B., Witschi, J. C., Littel, A. S. \& Fuller, R. K. (1971). Calorie and nutrient contribution of alcoholic beverages to the usual diets of 155 adults. American Journal of Clinical Nutrition 24, $1042-1052$.

Block, G., Dresser, C. M., Hartmann, A. M. \& Carrol, M. D. (1985). Nutrient sources in the American diet:quantitative data from the NHANES II survey. II. Macronutrients and fats. American Journal of Epidemiology 122, 27-40.

Christiansen, C., Thomsen, C., Rasmussen, O., Glerup, H., Bertelsen, J., Hansen, C., Ørskov, H. \& Hermansen, K. (1993). Acute effects of graded alcohol intake on glucose and insulin levels in non-insulin-dependent diabetic (NIDDM) subjects. European Journal of Clinical Nutrition 47, 648-652.

Connor, H. \& Marks, V. (1985). Alcohol and diabetes. Diabetic Medicine 2, 413-416.

Freinkel, N., Arky, R. A., Singer, D. L., Cohen, A. K., Bleicher, S. J., Anderson, J. B., Silbert, C. K. \& Foster, A. E. (1965). Alcohol hypoglycemia. IV. Current concepts of pathogenesis. Diabetes 14, 350-361.

Friedenberg, R., Metz, R., Mako, M.\& Surmaczynska, B. (1971). Differential plasma insulin response to glucose and glucagon stimulation following ethanol priming. Diabetes 6, 397-403.

Gin, H., Morlat, P., Ragnaud, J. M. \& Aubertin, J. (1992). Short-term effect of red wine (consumed during meals) on insulin requirement and glucose tolerance in diabetic patients. Diabetes Care 15, 546-548.

Machata, G. (1975). The advantages of automated blood alcohol determination by head space analysis. Zeitung der Rechtsmedizin 75, 229-234.

McMonagle, J. \& Felig, P. (1975). Effects of ethanol ingestion on glucose tolerance and insulin secretion in normal and diabetic subjects. Metabolism 5, 625-632.

Nikkilä, E. A. \& Taskinen, M. R. (1975). Ethanol-induced alterations of glucose tolerance, postglucose hypoglycemia, and insulin secretion in normal, obese and diabetic subjects. Diabetes 24, 933-943.

Ørskov, H., Thomsen, H. G. \& Yde, H. (1968). Wick chromatography for rapid and reliable immunoassay of insulin, glucagon and growth hormone. Nature 219, 193-195.

Thomson, M., Fulton, M., Elton, R. A., Brown, S., Wood, D. A. \& Oliver, M. F. (1988). Alcohol consumption and nutrient intake in middleaged Scottish men. American Journal of Clinical Nutrition 47, 139-145.

Walsh, C. H. \& O'Sullivan, D. J. (1974). Effects of moderate alcohol intake on control of diabetes. Diabetes 23, 440-442.

Windham, C. T., Wyse, B. W. \& Hansen, R. G. (1983). Alcohol consumption and nutrient density of diets in the Nationwide Food Consumption Survey. Journal of the American Dietetic Association 82, 364-373.

Yki Järvinen, H., Koivisto, V. A., Ylikahri, R. \& Taskinen, M. R. (1988). Acute effects of ethanol and acetate on glucose kinetics in normal subjects. American Journal of Physiology 254, E175-E180. 